AperTO - Archivio Istituzionale Open Access dell'Università di Torino

\title{
Adjustable and fixed interest rates mortgage markets modelling
}

\section{This is the author's manuscript}

Original Citation:

Availability:

This version is available http://hdl.handle.net/2318/140240

since 2018-03-13T17:45:00Z

Published version:

DOI:10.1007/s10100-013-0297-4

Terms of use:

Open Access

Anyone can freely access the full text of works made available as "Open Access". Works made available under a Creative Commons license can be used according to the terms and conditions of said license. Use of all other works requires consent of the right holder (author or publisher) if not exempted from copyright protection by the applicable law. 


\title{
Adjustable and fixed interest rates mortgage markets modelling. Evidences from Italy over the last fourteen years
}

\author{
Mariacristina Uberti $^{1}$, Simone Landini ${ }^{2}$, and Simone Casellina ${ }^{3}$ \\ ${ }^{1}$ Corresponding author: Department of Managment, Università degli Studi di Torino, C.so Unione \\ Sovietica 218/bis, 10134 Torino, Italy, mariacristina.uberti@unito.it \\ ${ }^{2}$ I.R.E.S. Piemonte, Turin, Italy \\ ${ }^{3}$ Banca d'Italia, Rome, Italy
}

\begin{abstract}
Due to recent developments in credit markets, the interdependencies among fixed rate mortgages (FRMs) and adjustable rate mortgages (ARMs) markets are analysed in the study of the interactions within credit markets since it appears very suitable and interesting. A meaningful and complete database of information on Financial Institutions (FIs) in Italy (1997:q1 - 2011:q4) hold by the Banca d'Italia shows that the relative importance of these markets recently displayed significant fluctuations since in 2005 fixed interest rate mortgage loans were about $10 \%$ while in 2009 they raised up to $70 \%$.

In the context of the FRMs and ARMs characteristics in Italian markets as well as the available database, among the proposed models for the study of interconnected markets (see Brock and Hommes (1997, 1998), Dieci and Westerhoff $(2009,2010)$ and related literature citetd therein), the models recently developed by Casellina et al. (2011) is applied to test its capacity to capture the dynamics of the observed data. It is worth stressing that the involved real data (volume of contracts and average interest rate in the FRMs and ARMs markets) are not sample information but they are evaluated on the entire population. The obtained findings point out the good level to fit the interest rates dynamics. Moreover, the model captures the switching mechanism and it catches the structural breaks when they occurs.
\end{abstract}

Keywords:mortgage market, price fluctuations, market interactions, adjustable and fixed rate mortgage, Italian markets

\section{Introduction and motivation}

The interdependencies among fixed rate mortgages (FRMs) and adjustable rate mortgages (ARMs) markets are analyzed since the choice to involve the data of mortgage loans in the study of the interactions within credit markets appears very suitable and interesting. A meaningful and complete database of information on Financial Institutions (FIs) in Italy (1997:q1 - 2011:q4) hold by the Banca d'Italia (BI) shows that the relative importance of these markets recently displayed significant fluctuations since in 2005 fixed interest rate mortgage loans were about $10 \%$ while in 2009 they raised up to $70 \%$.

The database is hold by the BI and it is meaningful and complete for both the extension and the accuracy of the available data, and it covers a period of 60 quarters.

The Italian anti-usury law provided that a maximum threshold was calculated for interest rates to apply for funding. This threshold varied with the technical form of financing: mortgages, leasing, employee loans and more. Moreover, the threshold varied each quarter and it was obtained for each technical form, increasing at most $50 \%$ the average rate charged in the previous quarter. So, on a quarterly basis, all banks and FIs operating in Italy were obliged by law to submit to the BI some information on their credit operations. In particular, for any technical form, they had to report the number of transactions in the quarter and the average rate charged on such transactions. Therefore, the FIs quarterly transmitted information as regarding their credit supply activities to BI that computed the average interest rate for each kind of contract the $i$-th institute supplied through the $t$-th quarter for the $k$-th kind of contract. Averaging over the whole population of FIs, the BI also computed the quarterly reference average interest rate $\rho_{k, t}$.

Within the credit market, the mortgage one is considered since it represents one of the most important financial market, at least in Italy where banks are more oriented toward a traditional business and families plan to buy a house as a primary investment option.

Over the past 25 years, the market for housing finance in industrial countries has changed and developed greatly and the literature concentrates primarily on two countries: the US and UK. An interesting systematic presentation of the state of research and the available literature is traceable in Leece (2004) (see also Bachofner and Lützkendorf (2005) and, recently, for example, Koijen et al. (2009), Coulibaly and Li (2009), Coles and Hardt (2000)).

As regards the euro area, the analysis and comparison of statistics on EU mortgage and housing markets are particularly interesting as well as data and information from several third countries such as the United States; these extensive analysis are available in several publications, e.g. the report of the European Mortgage Market Federation (EFM), the Working Papers of European Central Bank. The reactions of these markets to macroeconomic impulse as 


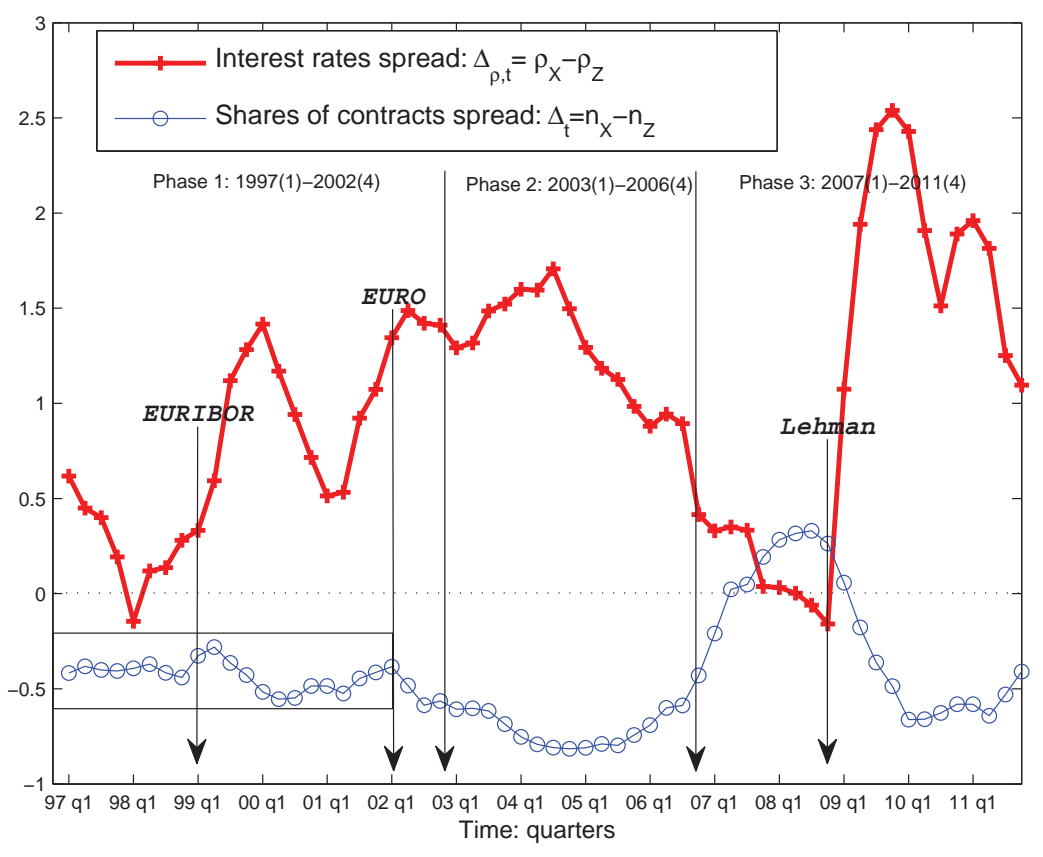

Figure 1: Interest rates and share of contracts spreads. Source: Bank of Italy

changes in monetary policy (see for example, Calza et al. (2009)). in terms of both prices and quantities (i.e. interest rates level and numbers of new contracts) could have a large impact on the balance sheets of banks, families as well as construction industrial sectors (see European Mortgage Federation (2012), Mori et al. (2009) and Coles and Hardt (2000)).

In the context of the characteristics of the FRMs and ARMs Italian markets as well as the available database, among the proposed models for the study of interconnected markets, the models recently developed by Dieci and Westerhoff $(2009,2010)$ and Casellina et al. (2011) are of particular interest due to their simplicity and adaptability at least as a first explorative approach.

Starting from the findings of Brock and Hommes (1997, 1998), and related literature citetd therein, based on a cobweb framework with linear demand and supply where producers (supply side) choose between rational and naïve expectations and a switching mechanism is introduced, Dieci and Westerhoff $(2009,2010)$ explore markets interdependences by enriching the cobweb framework. They introduce a switching mechanism depending on profit differences between markets where the market interactions are considered from the supply side and a fixed number of transactions through time is assumed. In a context of capital good Casellina et al. (2011) develop a model where the demand is driven in a cobweb framework, the switching mechanism depends on markets' profitability and the number of transactions changes through time.

On the basis of the available real data on both interest rates and transactions volumes, in this paper a joint mathematical-econometric model is setting up and developing to be able to capture the mechanisms of switching between the two mortgages markets as simply as possible. For this reason, the choice is turned on a cobweb linear model that, as rough and simple, it satisfies some interesting possibilities. For example, these markets are always in balance as it is not possible to store mortgage contracts because the mortgage market operates only just-in-time. This feature is easily implemented with a linear cobweb model type because it easy to solve it for the equilibrium conditions with respect to the guide variables, i.e., the interest rates. Being able to consider the rates as prices and the volumes of contract as quantities, their product interprets the market value, which is therefore equal to the value of supply and demand in balance at any date. The dynamic is expressed in a system of two coupled equations linked by an interaction factor, measured as the spread between the densities of the two kinds of contracts, which allows to take into account the switching mechanisms observed in real data.

This paper is organized as follows. The database is described and analysed in section 2; a cobweb modelling approach is outlined in section 3: after notation, in section 3.2 models of interaction between markets are explained taking into account the peculiarities of FRMs and ARMs Italian market; section 4 shows the results and estimates derived from the implementation of the proposed model by comparing also the real dynamics with those estimated both for interest rates and for mortgage market values; section 5 presents the conclusions.

\section{The database}

The available database gathers the following variables communicated to BI by Italian FIs at any quarter $t$ : the number $N_{X, t}$ and $N_{Z, t}$ of transactions and the average interest rates $\rho_{X, t}$ and $\rho_{Z, t}$ applied on the previous number of transactions concerning the $X$ FRMs market and the $Z$ ARMs market, respectively. In recent years, for these contracts interesting dynamics were observed in the difference of their prices and in the market shares $n_{X, t}=N_{X, t} / N_{t}$ and $n_{Z, t}=N_{Z, t} / N_{t}$, respectively, where $N_{t}=N_{X, t}+N_{Z, t}$ is the number of new contracts at any date $t$.

The series of spreads (see Figure 1) regarding the interest rates $\Delta_{\rho, t}=\rho_{X, t}-\rho_{Z, t}$ and the shares of transactions 
$\Delta_{t}=n_{X, t}-n_{Z, t}$ as well as the market values $V_{X, t}=\rho_{X, t} N_{X, t}$ and $V_{Z, t}=\rho_{Z, t} N_{Z, t}$ of FRMs and ARMs contracts, respectively, can be partitioned in some phases pointing out that, in general, a coordination exists between the series of spreads: when one increases, the other one decreases where the degree of coordination may vary from period to period.

If the coordination is measured by the correlation between the two spreads $\left(\Delta_{\rho, t}\right.$ and $\Delta_{t}$ for rates and shares, respectively) then the following values are observed according to the three phases (see Table 1): 1997:1 - 2002:4 $=-0.4946 ; 2003: 1-2006: 4=-0.6457 ; 2007: 1-2011: 4=-0.8578$. While for the whole series 1997:1 $-2011: 4$, the observed coordination is -035802 . Therefore for the whole series, it can be concluded that the degree of coordination is not high but it is consistent: as the two rates tend to approach, the difference between the volumes demanded is smaller. Instead, with reference to the three outlined phases of the series, it can be observed that the degree of coordination progressively increases, especially in the period that includes the beginning of the crisis.

For this reason, it can be useful to detail the discussion on the data where the three phases are determined with a typical Chartist approach (see Figure 1).

\section{Phase 1 1997:1-2002:4.}

The spread between the rates is always positive with higher fixed rate to floating rate, with the exception of 1998:1. The dynamics of this differential show wide fluctuations - for the most part over 100 basis points - reaching the maximum in 2002:2 to which approached in 2000:1. Between the shares of contracts the differential is always negative, because more and more ARM contracts are subscribed. This differential is of the order of $-50 \%$, i.e. the volumes of ARM contracts have been about double with respect to FRM ones. However, also the dynamics of this differential show fluctuations, although smaller in adjacent periods. However, in the period 1997:1-2002:4 the minimum differential was equal to $-28.11 \%$ (1999:2) while the maximum one was of $-58.64 \%$ (2002:3). In the period considered, between the interest rates spread and the shares spread the coordination - measured by the correlation - is equal to -0.5802 . This points out that the more the two rates tend to approach, the smaller is the difference between the demanded volumes.

\section{Phase 2 2003:1-2006:4.}

In this phase, shorter than the first one, a more coordination (-0.6457) is found. In fact it is clearly seen that when the spread between the interest rates increases, the spread between the shares decreases and vice versa. The inversion point is get in 2004:3, which corresponds to the maximum spread between FRM and ARM $\left(+1.7066: \rho_{Z}=\rho_{X}+1.7066\right)$. The maximum spread between the share of FRMs and ARMs is reached in 2004:4 with the value -0.8060 , i.e. the share of FRM contracts is $n_{X}=n_{Z}-80.60 \%$. Therefore, set 100 the share of the FRM contracts, the one of ARM contracts is equal to its $20 \%$ : this means that a FRM contract is signed on average every five ARM contracts.

\section{Phase 3 2007:1-2011:4.}

This phase contains the year before the crisis and it starts from 2007:1, but it shows the trends as a continuation of the previous phase. In fact, the spread between the shares is growing and, for the first time since 2007:2, it becomes positive: more FRMs are proportionately signed than ARMs. In this phase, the spread between the rates slows down and the fixed rate is only 50 basis points higher than the adjustable rate which appears as a weak incentive to take more risks with the adjustable rates. In fact, the spread between the shares remains positive throughout 2008, but since 2008:3 - that is the maximum point - the inversion begins that will lead this spread back negative in 2009:2.

The beginning of the financial crisis has changed the attitude in demand returned to prefer FRM also because it was granted the renegotiation on the margins of mortgages ${ }^{1}$. On the contrary, the spread between the interest rates becomes negative in 2008:2 and remains there until 2008:4 whereupon it takes a series of increments with wide jumps in growth that bring the spread between interest rates at historic maximum of 2009:4 with +2.5392 when the shares of FRMs contracts react with a negative spread of -0.3971. After 2009:4, the series of rate spreads begin to decay with some bounce and the spread series on the shares start to grow again, but in both cases, the levels of 2003 recur, when the crisis is still far away. So, 2010 is a phase of readjustment, perhaps obtained also thanks to the intervention of the supervisory authorities, after a period of dizziness concerning 2008 and 2009.

With particular reference to market value, it is interesting to highlight the interaction mechanism involving the switching, i.e. the intersections observed between the two trajectories (see Figure 2). Here, what is meant by switching and interaction can be anticipated: this is not to comply a FRM subscriber that passes to ARM market. There is no migration as occurs for the models in Brock and Hommes $(1997,1998)$ or Dieci and Westerhoff $(2009,2010)$ but a change in preferences is noticed, even though in this case, the profitability (the spread of rate respect to EURIBOR rate) drives the dynamics of the shares.

The interaction is therefore indirect and without migration of subscribers between the two markets. The market value is therefore influenced by two components: the volume of demands and the rate of the previous period because these lead the demand side preferences as well as the supply-side ones owing to the reference rate. Demand always coincides with supply, because these markets are always in equilibrium: in fact, it is not possible to have an excess of demand or supply. The contract is signed when needed and for that serves, if it is needed a home mortgage for 100.000 euro and the bank does not grant it but the bank offers a loan of 25.000 euro to buy a car, this contract is not signed because the house is need, not the car.

Moreover, it is interesting to note (see Figure 2) that the two sequences of market values are very well coordinated with each other. But, if the correlations are analysed: 1997:1-2011:4 $=-0,2851 ; 1997: 1-2002: 4=0,3157 ; 2003: 1$ 2006:4 $=0,3725 ; 2007: 1-2011: 4=0,1621$, throughout the series the correlation is negative although in the three

\footnotetext{
${ }^{1}$ For a microeconomic analysis of the Italian mortgage contracts and on the decrease in mortgage disbursements in Italy from $2008-2011$, see the Bank of Italy report Felici et al. (2012). From this study, it appears that borrowers younger and those not belonging to non-EU countries were most affected by the worsening of economic cycle as well as by the more selective policies from banks.
} 
Table 1: Correlations of the model variables with respect to the three phases. Each panel refers to separate phases: top panel for the whole period. In each panel four groups of variables are identified: interest rates and their spreads; volumes or number of subscribed contracts; shares of contracts and their spreads; market values as the product of the interest rate with the volume of contracts in each market. $(*)$ In case of correlation with the EURIBOR interest rate, time series begin on $1999: 1$.

\begin{tabular}{|c|c|c|c|c|c|c|c|c|c|c|c|}
\hline $97: 1-11: 4$ & $\rho_{X}$ & $\rho_{Z}$ & $\Delta \rho$ & $N_{X}$ & $N_{Z}$ & $N$ & $n_{X}$ & $n_{Z}$ & $\Delta n$ & $V_{X}$ & $V_{Z}$ \\
\hline $\begin{array}{c}\rho_{X} \\
\rho_{Z} \\
\Delta \rho\end{array}$ & $\begin{array}{c}1.00 \\
0.94 \\
-0.47\end{array}$ & $\begin{array}{c}1.00 \\
-0.74\end{array}$ & 1.00 & & & & & & & & \\
\hline $\begin{array}{c}N_{X} \\
N_{Z} \\
N\end{array}$ & $\begin{array}{l}-0.16 \\
-0.69 \\
-0.78\end{array}$ & $\begin{array}{c}0.04 \\
-0.76 \\
-0.71\end{array}$ & $\begin{array}{c}-0.41 \\
0.62 \\
0.31\end{array}$ & $\begin{array}{c}1.00 \\
-0.30 \\
0.39\end{array}$ & $\begin{array}{l}1.00 \\
0.76\end{array}$ & 1.00 & & & & & \\
\hline $\begin{array}{l}n_{X} \\
n_{Z} \\
\Delta n \\
\end{array}$ & $\begin{array}{c}0.07 \\
-0.17 \\
0.09 \\
\end{array}$ & $\begin{array}{c}0.27 \\
-0.36 \\
0.29 \\
\end{array}$ & $\begin{array}{c}-0.57 \\
0.60 \\
-0.58 \\
\end{array}$ & $\begin{array}{c}0.92 \\
-0.90 \\
0.92 \\
\end{array}$ & $\begin{array}{c}-0.55 \\
0.67 \\
-0.58 \\
\end{array}$ & $\begin{array}{l}0.10 \\
0.03 \\
0.06 \\
\end{array}$ & $\begin{array}{c}1.00 \\
-0.96 \\
1.00 \\
\end{array}$ & $\begin{array}{c}1.00 \\
-0.98 \\
\end{array}$ & 1.00 & & \\
\hline $\begin{array}{l}V_{X} \\
V_{Z} \\
\end{array}$ & $\begin{array}{c}0.04 \\
-0.03 \\
\end{array}$ & $\begin{array}{l}0.23 \\
0.00 \\
\end{array}$ & $\begin{array}{l}-0.53 \\
-0.05 \\
\end{array}$ & $\begin{array}{c}0.98 \\
-0.30 \\
\end{array}$ & $\begin{array}{c}-0.45 \\
0.57 \\
\end{array}$ & $\begin{array}{l}0.23 \\
0.35 \\
\end{array}$ & $\begin{array}{c}0.95 \\
-0.44 \\
\end{array}$ & $\begin{array}{c}-0.94 \\
0.50 \\
\end{array}$ & $\begin{array}{c}0.95 \\
-0.46 \\
\end{array}$ & $\begin{array}{c}1.00 \\
-0.29 \\
\end{array}$ & 1.00 \\
\hline$E U R I B O R^{*}$ & 0.84 & 0.98 & -0.79 & 0.33 & -0.59 & -0.36 & 0.42 & -0.43 & 0.43 & 0.45 & 0.25 \\
\hline $97: 1-02: 4$ & $\rho_{X}$ & $\rho_{Z}$ & $\Delta \rho$ & $N_{X}$ & $N_{Z}$ & $N$ & $n_{X}$ & $n_{Z}$ & $\Delta n$ & $V_{X}$ & $V_{Z}$ \\
\hline $\begin{array}{c}\rho_{X} \\
\rho_{Z} \\
\Delta \rho \\
\end{array}$ & $\begin{array}{c}1.00 \\
0.96 \\
-0.37 \\
\end{array}$ & $\begin{array}{c}1.00 \\
-0.62 \\
\end{array}$ & 1.00 & & & & & & & & \\
\hline $\begin{array}{c}N_{X} \\
N_{Z} \\
N \\
\end{array}$ & $\begin{array}{l}-0.73 \\
-0.70 \\
-0.77 \\
\end{array}$ & $\begin{array}{l}-0.73 \\
-0.82 \\
-0.85 \\
\end{array}$ & $\begin{array}{l}0.36 \\
0.74 \\
0.69 \\
\end{array}$ & $\begin{array}{l}1.00 \\
0.64 \\
0.80 \\
\end{array}$ & $\begin{array}{l}1.00 \\
0.97 \\
\end{array}$ & 1.00 & & & & & \\
\hline $\begin{array}{l}n_{X} \\
n_{Z} \\
\Delta n\end{array}$ & $\begin{array}{c}0.02 \\
-0.05 \\
0.03\end{array}$ & $\begin{array}{c}0.16 \\
-0.19 \\
0.17 \\
\end{array}$ & $\begin{array}{c}-0.49 \\
0.50 \\
-0.49 \\
\end{array}$ & $\begin{array}{c}0.36 \\
-0.34 \\
0.36 \\
\end{array}$ & $\begin{array}{c}-0.47 \\
0.49 \\
-0.48 \\
\end{array}$ & $\begin{array}{c}-0.26 \\
0.28 \\
-0.27 \\
\end{array}$ & $\begin{array}{c}1.00 \\
-1.00 \\
1.00 \\
\end{array}$ & $\begin{array}{c}1.00 \\
-1.00 \\
\end{array}$ & 1.00 & & \\
\hline $\begin{array}{c}V_{X} \\
V_{Z} \\
\end{array}$ & $\begin{array}{c}-0.14 \\
0.06 \\
\end{array}$ & $\begin{array}{l}-0.18 \\
-0.03 \\
\end{array}$ & $\begin{array}{l}0.21 \\
0.28 \\
\end{array}$ & $\begin{array}{l}0.75 \\
0.07 \\
\end{array}$ & $\begin{array}{l}0.36 \\
0.57 \\
\end{array}$ & $\begin{array}{l}0.51 \\
0.47 \\
\end{array}$ & $\begin{array}{c}0.43 \\
-0.61 \\
\end{array}$ & $\begin{array}{c}-0.43 \\
0.60 \\
\end{array}$ & $\begin{array}{c}0.43 \\
-0.61 \\
\end{array}$ & $\begin{array}{l}1.00 \\
0.32 \\
\end{array}$ & 1.00 \\
\hline EURIBOR* & 0.82 & 0.98 & -0.42 & -0.60 & -0.14 & -0.40 & -0.50 & 0.48 & -0.50 & -0.33 & 0.61 \\
\hline $03: 1-06: 4$ & $\rho_{X}$ & $\rho_{Z}$ & $\Delta \rho$ & $N_{X}$ & $N_{Z}$ & $N$ & $n_{X}$ & $n_{Z}$ & $\Delta n$ & $V_{X}$ & $V_{Z}$ \\
\hline $\begin{array}{c}\rho_{X} \\
\rho_{Z} \\
\Delta \rho \\
\end{array}$ & $\begin{array}{l}1.00 \\
0.49 \\
0.26 \\
\end{array}$ & $\begin{array}{c}1.00 \\
-0.71 \\
\end{array}$ & 1.00 & & & & & & & & \\
\hline $\begin{array}{c}N_{X} \\
N_{Z} \\
N \\
\end{array}$ & $\begin{array}{c}0.18 \\
-0.77 \\
-0.64 \\
\end{array}$ & $\begin{array}{c}0.85 \\
-0.39 \\
0.01 \\
\end{array}$ & $\begin{array}{l}-0.79 \\
-0.18 \\
-0.53 \\
\end{array}$ & $\begin{array}{c}1.00 \\
-0.09 \\
0.36 \\
\end{array}$ & $\begin{array}{l}1.00 \\
0.90 \\
\end{array}$ & 1.00 & & & & & \\
\hline $\begin{array}{l}n_{X} \\
n_{Z} \\
\Delta n\end{array}$ & $\begin{array}{c}0.44 \\
-0.46 \\
0.45\end{array}$ & $\begin{array}{c}0.91 \\
-0.90 \\
0.91\end{array}$ & $\begin{array}{c}-0.65 \\
0.63 \\
-0.65\end{array}$ & $\begin{array}{c}0.93 \\
-0.92 \\
0.92 \\
\end{array}$ & $\begin{array}{c}-0.44 \\
0.46 \\
-0.45\end{array}$ & $\begin{array}{l}0.01 \\
0.02 \\
0.00\end{array}$ & $\begin{array}{c}1.00 \\
-1.00 \\
1.00\end{array}$ & $\begin{array}{c}1.00 \\
-1.00 \\
\end{array}$ & 1.00 & & \\
\hline $\begin{array}{l}V_{X} \\
V_{Z} \\
\end{array}$ & $\begin{array}{c}0.28 \\
-0.53 \\
\end{array}$ & $\begin{array}{l}0.88 \\
0.19 \\
\end{array}$ & $\begin{array}{l}-0.75 \\
-0.64 \\
\end{array}$ & $\begin{array}{l}0.99 \\
0.44 \\
\end{array}$ & $\begin{array}{c}-0.17 \\
0.83 \\
\end{array}$ & $\begin{array}{l}0.28 \\
0.97\end{array}$ & $\begin{array}{l}0.96 \\
0.11 \\
\end{array}$ & $\begin{array}{l}-0.94 \\
-0.07 \\
\end{array}$ & $\begin{array}{l}0.95 \\
0.09 \\
\end{array}$ & $\begin{array}{l}1.00 \\
0.37 \\
\end{array}$ & 1.00 \\
\hline EURIBOR & 0.46 & 0.99 & -0.73 & 0.83 & -0.38 & 0.01 & 0.89 & -0.89 & 0.89 & 0.86 & 0.19 \\
\hline $07: 1-11: 4$ & $\rho_{X}$ & $\rho_{Z}$ & $\Delta \rho$ & $N_{X}$ & $N_{Z}$ & $N$ & $n_{X}$ & $n_{Z}$ & $\Delta n$ & $V_{X}$ & $V_{Z}$ \\
\hline $\begin{array}{c}\rho_{X} \\
\rho_{Z} \\
\Delta \rho \\
\end{array}$ & $\begin{array}{c}1.00 \\
0.90 \\
-0.76 \\
\end{array}$ & $\begin{array}{c}1.00 \\
-0.96 \\
\end{array}$ & 1.00 & & & & & & & & \\
\hline $\begin{array}{c}N_{X} \\
N_{Z} \\
N \\
\end{array}$ & $\begin{array}{c}0.90 \\
-0.81 \\
0.07 \\
\end{array}$ & $\begin{array}{c}0.93 \\
-0.84 \\
0.06 \\
\end{array}$ & $\begin{array}{c}-0.85 \\
0.78 \\
-0.05 \\
\end{array}$ & $\begin{array}{c}1.00 \\
-0.80 \\
0.24 \\
\end{array}$ & $\begin{array}{l}1.00 \\
0.39 \\
\end{array}$ & 1.00 & & & & & \\
\hline $\begin{array}{l}n_{X} \\
n_{Z} \\
\Delta n\end{array}$ & $\begin{array}{c}0.87 \\
-0.90 \\
0.88\end{array}$ & $\begin{array}{c}0.91 \\
-0.93 \\
0.92\end{array}$ & $\begin{array}{c}-0.85 \\
0.86 \\
-0.86\end{array}$ & $\begin{array}{c}0.93 \\
-0.96 \\
0.94\end{array}$ & $\begin{array}{c}-0.90 \\
0.93 \\
-0.91\end{array}$ & $\begin{array}{c}-0.02 \\
0.03 \\
-0.02\end{array}$ & $\begin{array}{c}1.00 \\
-0.98 \\
1.00\end{array}$ & $\begin{array}{c}1.00 \\
-0.99 \\
\end{array}$ & 1.00 & & \\
\hline $\begin{array}{l}V_{X} \\
V_{Z} \\
\end{array}$ & $\begin{array}{l}0.92 \\
0.14 \\
\end{array}$ & $\begin{array}{l}0.94 \\
0.24 \\
\end{array}$ & $\begin{array}{l}-0.86 \\
-0.28 \\
\end{array}$ & $\begin{array}{l}1.00 \\
0.16 \\
\end{array}$ & $\begin{array}{c}-0.81 \\
0.27 \\
\end{array}$ & $\begin{array}{l}0.23 \\
0.69 \\
\end{array}$ & $\begin{array}{c}0.94 \\
-0.11 \\
\end{array}$ & $\begin{array}{c}-0.96 \\
0.05 \\
\end{array}$ & $\begin{array}{c}0.95 \\
-0.10 \\
\end{array}$ & $\begin{array}{l}1.00 \\
0.16 \\
\end{array}$ & 1.00 \\
\hline EURIBOR & 0.89 & 0.99 & -0.95 & 0.92 & -0.77 & 0.16 & 0.89 & -0.90 & 0.89 & 0.93 & 0.31 \\
\hline
\end{tabular}




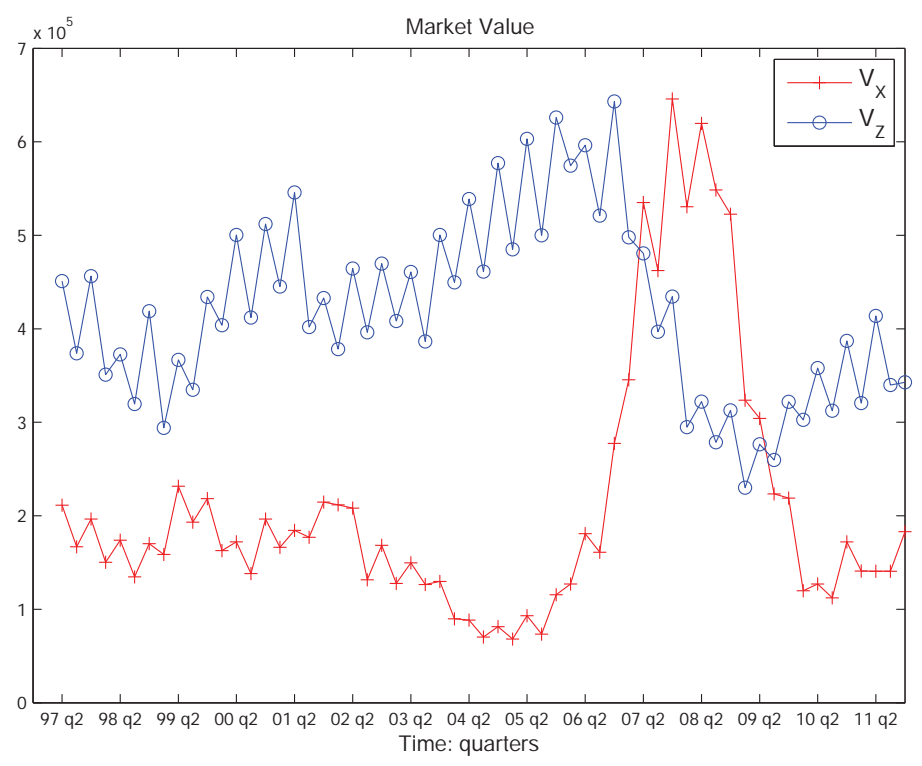

Figure 2: Fixed and adjustable market values series.

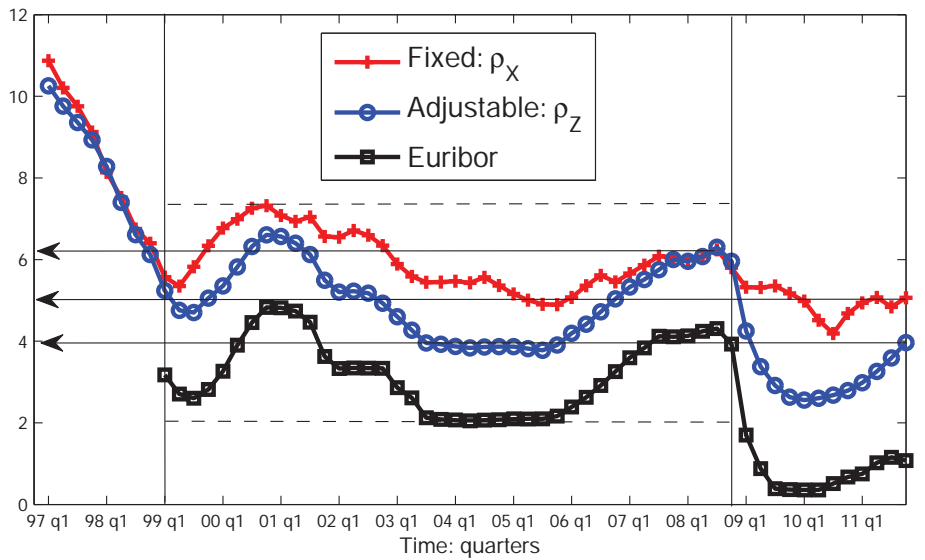

Figure 3: Fixed, adjustable and EURIBOR interes rates series. 
sub-periods it is always positive and with an intensity that in the third phase is reduced by half. This suggests that there is an underlying trend that induces the market value of ARM to decrease whereas the FRM one tends to drive growth. This trend can not be generalized because, depending on the period, the propensity of customers changes and this determines the interaction between the two markets that leads to the switching of the two series. In particular, the two series intersect at two specific dates, 2007:1 and 2009:2, one year before and one after the outbreak of the crisis. But, above all, in 2011 it is noted that the two series both grow even if the spreads of the rates and the ones of the shares had hinted that rates and shares are approaching. Furthermore, in both series a sequence of $\ldots+/-/+/-$ can be observed: there are but a few of two consecutive periods in which market values increase or decrease, but they are always ups and downs. This is due to the interaction between price and volume where today's price is a function of past price but also of today's volume.

\section{A cobweb modelling approach}

\subsection{Notation}

Notation and some basic assumptions of the proposed interacting mortgage market model are briefly introduced, referring to the paper of Casellina et al (2011) also for further detailed explanations and insights on the theoretical framework.

Let $X$ and $Z$ be then the two sub-markets where $X$ and $Z$ refer to FRMs and ARMs, respectively.

The quantities are given by the equilibrium level of transactions $N_{X, t}$ and $N_{Z, t}$ closed by the FIs in the $t$-th quarter. One segment of the market is considered that it is split into two sub-markets of FRM contracts and ARMs contracts consistently to Dieci and Westerhoff $(2009,2010)$ cobweb model.

Markets clear at every time, that is every demand level is satisfied at each time and each customer can buy only one credit good at time so that $N_{t}=N_{X, t}+N_{Z, t}$ is the total number of transactions. The model manages to mimic the shares dynamics of contracts, $n_{X, t}=N_{X, t} / N_{t}$ and $n_{Z, t}=1-n_{X, t}$, but, differently from the model in Dieci and Westerhoff $(2009,2010)$, the total number of transactions is not fixed, rather it changes through time. According to this assumption, the representative FI taxonomy can be substituted with a credit contract taxonomy.

\subsection{Two-factor interacting market models}

Aggregate supply is defined as a linear function on the previous period interest rate

$$
\left\{\begin{array}{c}
S_{X, t}=-\alpha_{X}+\beta_{X} \rho_{X, t-1} \\
S_{Z, t}=-\gamma_{Z}+\delta_{Z} \rho_{Z, t-1}
\end{array}\right.
$$

while aggregate demand is

$$
\left\{\begin{array}{ccc}
D_{X, t}=N_{t} n_{X, t} d_{X, t} & : \quad d_{X, t}=a_{X}-b_{X} \rho_{X, t} \\
D_{Z, t}=N_{t} n_{Z, t} d_{Z, t} & : \quad d_{Z, t}=c_{Z}-d_{Z} \rho_{Z, t}
\end{array}\right.
$$

where the coefficients $\alpha_{X}, \beta_{X}, \gamma_{Z}, \delta_{Z}, a_{X}, b_{X}, c_{Z}$ and $d_{Z}$ are positive real numbers.

Referring to the model in Casellina et al. (2011) to infer how the distribution of profits and transactions looks like, without having at hands real data, the fraction of clients in each segment - i.e. $n_{k, t}=N_{k, t} / N_{t}$ - was assumed to maximize the entropy at the system level by solving the following problem

$$
\left\{\begin{array}{c}
\max -\sum_{k=X, Z} n_{k, t} \log n_{k, t} \quad \text { s.t. } \\
\sum_{k=X, Z} n_{k, t}=1 \\
\sum_{k=X, Z} N_{t} n_{k, t} \pi_{k, t}=\pi_{t}
\end{array}\right.
$$

where $\pi_{k, t}=\left(1+\vartheta_{k}\right)\left(\rho_{k, t-1}-\iota_{t-1}\right)$ was the average profit estimate that can be defined as a market specific markup on the previous period spread between the price $\rho_{k, t-1}$ and the interest rate $\iota_{t-1}$ that represented an EURIBOR-like interbank interest rate assumed to follow an $\mathrm{AR}(1)$ process. Therefore

$$
\hat{n}_{k, t}=\frac{e^{-\beta N_{t} \pi_{k, t}}}{\mathcal{Z}(\beta)} \quad: \quad k=X, Z
$$

where $\mathcal{Z}(\beta)=\sum_{k} e^{-\beta N_{t} \pi_{k, t}}$ was the partition function.

Since, by assumption, the volume of transactions changes over time, the following logistic curve was involved as a variable to modulate the dynamics of interest rates $\rho_{X, t}$ and $\rho_{Z, t}$

$$
N_{t}=N_{t-1}\left(P-Q N_{t-1}\right)
$$

where $P=1+r$, being $r$ the growth rate of transactions, and $Q=r / M$, being $M$ the capacity of the system.

According to Dieci and Westerhoff $(2009,2010)$ DW model, the difference of the two state cardinalities was defined by

$$
\Delta_{t}=n_{X, t}-n_{Z, t}=\frac{e^{-\beta N_{t} \pi_{X, t}}-e^{-\beta N_{t} \pi_{Z, t}}}{\mathcal{Z}(\beta)}=2 n_{X, t}-1 \Rightarrow\left\{\begin{array}{c}
n_{X, t}=\frac{1+\Delta_{t}}{2} \\
n_{Z, t}=\frac{1-\Delta_{t}}{2}
\end{array}\right.
$$

and then from the equilibrium conditions $D_{k, t}=S_{k, t}$, for $k=X, Z$, it followed that

$$
\left\{\begin{array}{c}
\rho_{X, t}=\frac{a_{X}}{b_{X}}-\left(\frac{\beta_{X}}{b_{X}} \rho_{X, t-1}-\frac{\alpha_{X}}{b_{X}}\right) \frac{2}{N_{t}\left(1+\Delta_{t}\right)} \\
\rho_{Z, t}=\frac{c_{Z}}{d_{Z}}-\left(\frac{\delta_{Z}}{d_{Z}} \rho_{Z, t-1}-\frac{\gamma_{Z}}{d_{Z}}\right) \frac{2}{N_{t}\left(1-\Delta_{t}\right)}
\end{array}\right.
$$




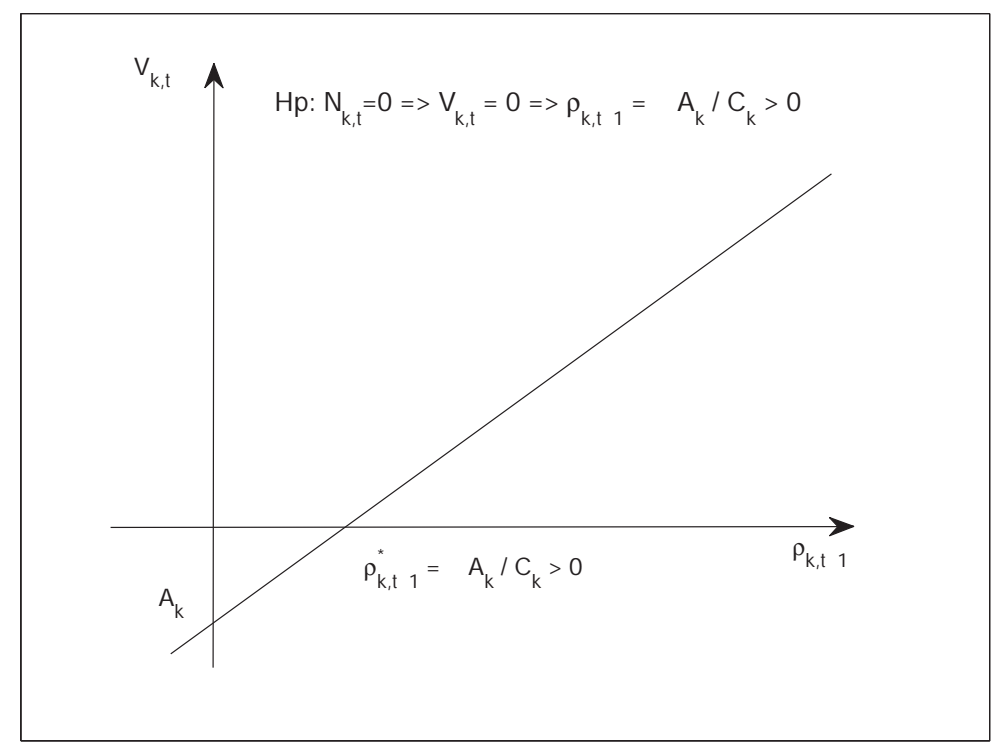

Figure 4: Interpretation of $\rho_{k, t-1}^{*}$ as a threshold of the constant term in the econometric models.

Table 2: OLS estimates of equation (8).

\begin{tabular}{llllll}
\hline $\begin{array}{l}\text { Fixed } \\
\text { Int. Rate }\end{array}$ & Param. & $\begin{array}{l}\text { Std. } \\
\text { Err }\end{array}$ & $\begin{array}{l}\text { Adjustable } \\
\text { Int. Rate }\end{array}$ & Param. & $\begin{array}{l}\text { Std. } \\
\text { Err. }\end{array}$ \\
\hline$\rho_{X, t-1}$ & $19,647.00$ & $8,009.47$ & $\rho_{Z, t-1}$ & $55,994.96$ & $62,007.93$ \\
$N_{X, t}$ & 5.99 & $1,163.67$ & $N_{Z, t}$ & 4.10 & $6,464.05$ \\
const. & $-122,224.72$ & 0.07 & const. & $-242,740.77$ & 0.35 \\
\hline$\rho_{X, t-1}^{*}$ & 6.22 & & $\rho_{Z, t-1}^{*}$ & 4.34 & \\
\hline$R^{2} a d j$. & 0,9929 & & $R^{2} a d j$. & 0,7020 & \\
\hline Ons. & 59 & & Obs. & 59 & \\
\hline
\end{tabular}

from which it appears that the two equations were still coupled and the difference term $\Delta_{t}$ was an interaction term: in the long run it vanished if transactions' distribution polarized on equal probabilities of $1 / 2$ for each market. Moreover, $\Delta_{t}$ depended on one of the $n_{k, t}$ (i.e. $n_{X, t}$ in our case) which was a function of the estimate $\pi_{k, t}$ defined to be proportional to the spread $\rho_{k, t-1}-\iota_{t-1}$. Therefore, the stochastic dynamics involved into (7) was only due to the exogenous interest rate $\iota_{t}$.

Finally, equilibrium conditions lead to the mathematical model (7) which entails the following equations that can be econometrically estimated

$$
\left\{\begin{array}{c}
V_{X, t}=\rho_{X, t} N_{X, t}=A_{X}+B_{X} N_{X, t}+C_{X} \rho_{X, t-1} \\
V_{Z, t}=\rho_{Z, t} N_{Z, t}=A_{Z}+B_{Z} N_{Z, t}+C_{Z} \rho_{Z, t-1}
\end{array}\right.
$$

where $A_{X}=\frac{\alpha_{X}}{b_{X}}, B_{X}=\frac{a_{X}}{b_{X}}$ and $C_{X}=-\frac{\beta_{X}}{b_{X}} ; A_{Z}=\frac{\gamma_{Z}}{d_{Z}}, B_{Z}=\frac{c_{Z}}{d_{Z}}$ and $C_{Z}=-\frac{\delta_{Z}}{d_{Z}}$

If there is not any demand or signed mortgage contracts, the market value would be zero. So the constant $\rho_{k, t}=-A_{k} / C_{k}>0, k=X, Y$, can be interpreted as the rate threshold for formulating a supply of contracts (see Figure 4).

\section{Results and estimates}

Considering $N_{k, t}$ as quantities and $\rho_{k, t}$ as prices in both FRM $(k=X)$ and $\operatorname{ARM}(k=Z)$ markets, respectively, it follows that $V_{k, t}$ of (8) can be read as the value of the $k$ market at date $t$. In fact, from the equilibrium conditions of the cobweb model, it results that these markets are always in equilibrium because goods are not storable. By the equations (8), it is possible to estimate the effect current of the volume of contracts and the rate past on the current value of the single market. The estimate results are collected in the Table 2 .

As regards the market value dynamics, Figure 5 shows the overlapping of the real data series with those obtained from the analytical model, whose parameters have been estimated econometrically. The model's ability to capture the background dynamics - particularly in times of switches and at the points of structural break - it is due to the fact that the model is not an econometric standard model but it is an hybrid one: mathematical as regards the implementation of the theory described by the cobweb setting, and econometric as regards the econometric estimators used to calibrate the parameters. 


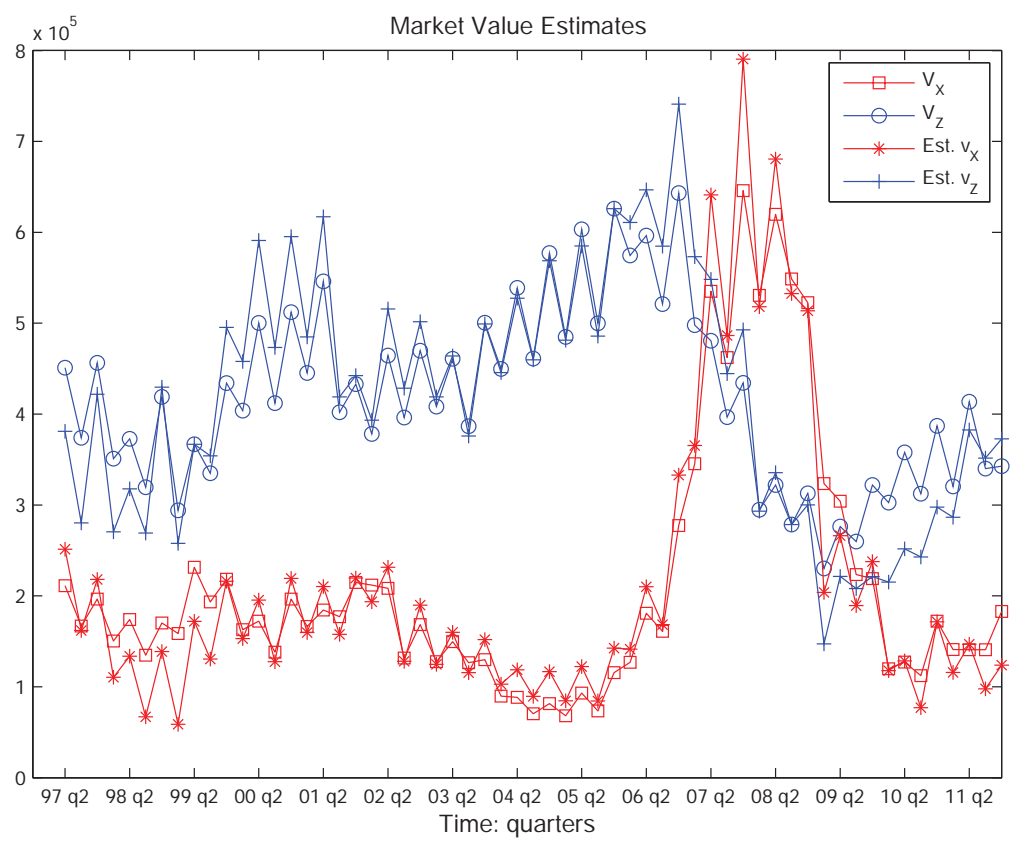

Figure 5: Market values: real and estimated time series.

The estimated curves consider only the initial conditions and then prognostically replicate the dynamics by using the proposed analytical model on the basis of parameters econometrically calibrated (7) where the only exogenous variable is the EURIBOR rate, as introduced in (3). In fact, the EURIBOR rate is used to calculate the profit that is the driving variable in the maximum entropy model for the density of the contracts, whose spread is given by the $\Delta_{t}$ quantity.

Just thanks to this $\Delta_{t}$ variable, it is possible to refer to interaction between the two markets - although not as a direct interaction - and this makes coupled the two equations, thus allowing to catch the switch between the two series. However it should be noted that switching must not to mean the transition of some customers from one market to another one. In fact, only rarely signed contracts are renegotiated in order to change the nature, on the other hand the mortgage contracts considered here are "all possible" mortgage contracts, therefore similar migrations can not be isolated. Instead, the change in the customer preferences in the market (in this case the Italian one) is considered as a switch.

For example, between 2007 and 2009 the market value of FRMs has exceeded that of ARMs showing a better preference for the former at the expense of the latter: thus the $2007 \mathrm{q} 2$ and $2009 \mathrm{q} 3$ are the change points of this preference.

The good model performance is remarkable by the ability to well replicate the dynamics of interest rates. Indeed, by dividing the estimated market value for the actual number of contracts, an indirect estimation of the interest rates is given to be compared with their actual values.

The Figure 6 shows the overlap between real and reproduced series, where as a proxy of interest rate estimates it has been used the ration of the estimated market value on the real volume of contracts. In both cases the character of the dynamics is captured, although there are some points where the overlap is not precise, which is also detectable in the dynamics of market values. For example, in the case of fixed rates, in the last part of the series, a mismatch is observed particularly in 2010q2. This phase shift is due to the fact that the theoretical model is based on the solution of the logistics used to interpret the dynamics of the volumes.

\section{Conclusions}

This paper involves an aggregate demand driven model to analyse some features on the dynamics of fixed and adjustable interest rates market emerging from real data in Italy since the first quarter of 1997 up to the last quarter of 2011. The database is hold by the BI and it is meaningful and complete for both the extension and the accuracy of the available data, and it covers a period of 60 quarters.

In this market two broad kinds of mortgages contracts are offered: fixed-rate and adjustable-rate and the database of the BI collects the relative information distinguishing between these two operations. In recent years, interesting dynamics were observed in the market share for these contracts and in the difference of their prices, (see Figure 1). In fact, it is important to point out that the relative importance of such contracts displayed modifications (also in Italy): for instance, in 2005 fixed interest rate mortgage loans were about $10 \%$ while in 2008 they raised up to $70 \%$. Moreover, large deviations were observed over time in the relative share of fixed rate mortgages such that the choice to involve the data of mortgage loans in the study of the interactions within credit markets appears very suitable and interesting. The observed specular dynamics of fixed vs. adjustable interest rate suggest that the structure of an aggregate cobweb model type could be easy to handle for the analysis of interconnected markets, at least as a first approach.

Therefore, in this paper, starting from a recent interconnected cobweb market model in Dieci and Westerhoff (2009, 


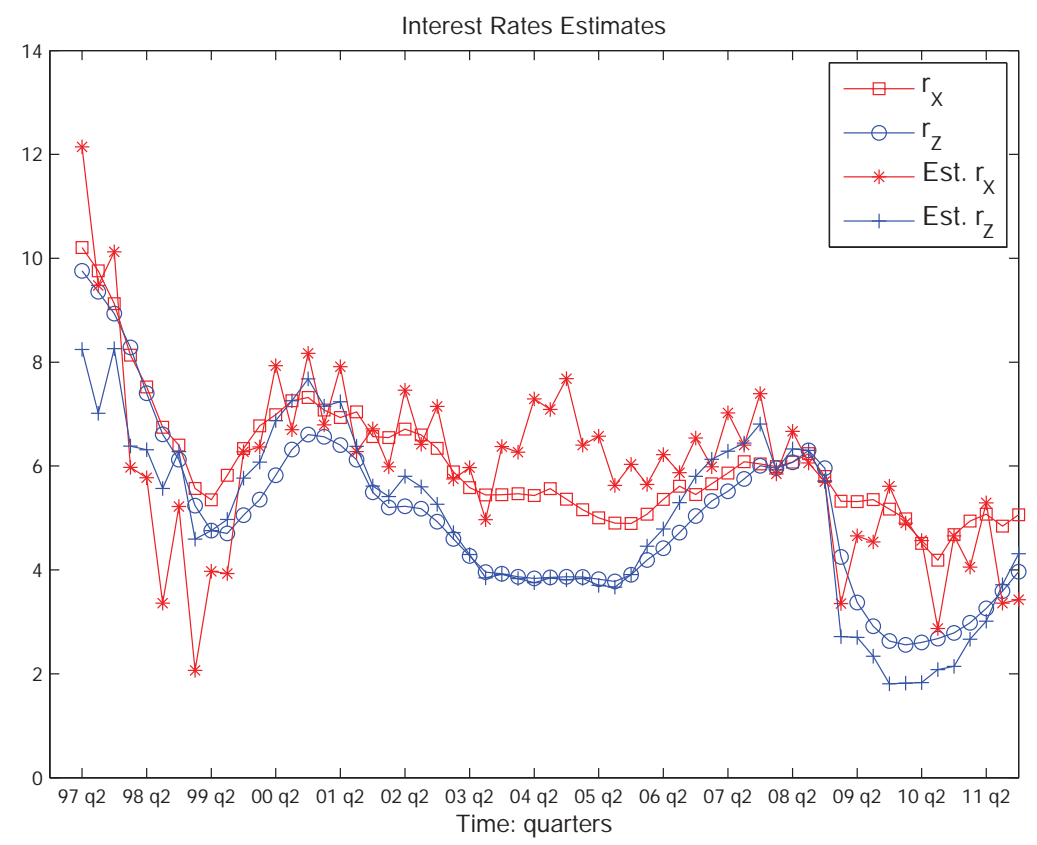

Figure 6: Real and estimated interest rates time series. Estimated interest rates are ratios of estimated market values over real number of contracts in each market.

2010), and the findings of Brock and Hommes (1997, 1998), in Casellina et al. (2011) is applied to test its capacity to capture the dynamics of the observed data. It is worth stressing that the involved real data (volume of contracts and average interest rate in the two mortgage markets) are not sample information but they are evaluated on the entire population.

Up to now, the obtained findings point out the good level of fit of the equations in Casellina et al. (2011) for the interest rates dynamics. The model captures the switching mechanism and it catches the structural breaks when they occurs. It must be considered that the evolution of the estimated series (see Figure 5 and Figure 6) considers only the initial data, the estimated parameters and the EURIBOR (the only exogenous variable).

Generally, the model shows a good overlap between the dynamics of real and reproduced series. It is noted, however, that at the end of the series there is not a precise overlapping owing to the fact that the logistics on $N_{t}$ is used as a driver of the tendency to interpret the dynamics of the volumes.

Although the obtained results are satisfactory, the simplicity of the model does not allow a precise overlapping of the estimated values with the real ones, therefore for purposes of prediction its use does not seem appropriate to the current level of specification.

However, it can be considered as a methodological approach improving on this satisfactory starting point. In fact, there are some points that are worthy to be treated further, like the logistic equation that drives the volumes dynamics in the simulation to estimate the indirect interest rates to compare with the real ones.

The ambition of the proposed model is therefore purely methodological: to evaluate the possibility for an analytical model - resulting from a basic theory implemented with the cobweb approach - to interpret the dynamics between interacting markets, even beyond an econometric approach. Therefore, the explanation is traced in the theoretical starting framework, namely the experimental results obtained should be read in the cobweb models setting.

Acknowledgements Authors are grateful to two anonymous referees for comments which have improved the paper and led to this final version. This research was partially supported by MIUR (Ministero dell'Istruzione, dell'Università e della Ricerca scientifica), Italy. The views and opinions expressed by the authors are their own and do not involve the responsibility of the institutions to which they belong to. 


\section{Appendix: Characteristics of main references}

\begin{tabular}{|l|l|l|}
\hline \hline Author(s) & Title & Characteristics \\
\hline \hline $\begin{array}{l}\text { Brock Wommes C. H. } \\
(1997)\end{array}$ & $\begin{array}{l}\text { A rational route to } \\
\text { randomness }\end{array}$ & $\begin{array}{l}\text { heterogeneous beliefs; } \\
\text { adaptive learning; busi- } \\
\text { ness cycles; cobweb } \\
\text { model; homoclinic bifur- } \\
\text { cations; strange attractors }\end{array}$ \\
\hline $\begin{array}{l}\text { Brock Wommes C. H., } \\
\text { (1998) }\end{array}$ & $\begin{array}{l}\text { Heterogeneous be- } \\
\text { liefs and routes to } \\
\text { chaos in a simple } \\
\text { asset pricing model }\end{array}$ & $\begin{array}{l}\text { asset pricing; heteroge- } \\
\text { neous beliefs; bifurcation }\end{array}$ \\
\hline $\begin{array}{l}\text { Casellina S., Lan- } \\
\text { dini S., Uberti M. } \\
\text { (2011) }\end{array}$ & $\begin{array}{l}\text { Credit market dy- } \\
\text { namics: a cobweb } \\
\text { model }\end{array}$ & $\begin{array}{l}\text { credit market; price fluc- } \\
\text { tuations; market interac- } \\
\text { tions; interest rate dy- } \\
\text { namics; nonlinear dynam- } \\
\text { ics }\end{array}$ \\
\hline $\begin{array}{l}\text { Dieci R., Wester- } \\
\text { hoff F. (2009) }\end{array}$ & $\begin{array}{l}\text { Stability analy- } \\
\text { sis of a cobweb } \\
\text { model with market } \\
\text { interactions }\end{array}$ & $\begin{array}{l}\text { cobweb model; interacting } \\
\text { markets; bounded ratio- } \\
\text { nality; stability; bifurca- } \\
\text { tion analysis }\end{array}$ \\
\hline $\begin{array}{l}\text { Dieci R., Wester- } \\
\text { hoff F. (2010) }\end{array}$ & $\begin{array}{l}\text { Interacting cobweb } \\
\text { markets }\end{array}$ & $\begin{array}{l}\text { price fluctuations; market } \\
\text { interactions; risk aversion; } \\
\text { nonlinear dynamics; bifur- } \\
\text { cation analysis }\end{array}$ \\
\hline
\end{tabular}

\section{References}

Bachofner, M. and Lützkendorf, T. (2005). Research trends in the mortgage market, Building Research and Information, 33(4), 376-381.

Brock, W.A. and Hommes, C.H. (1997). A rational route to randomness, Econometrica, 65(5), 1059-1095.

Brock, W.A. and Hommes, C.H. (1998). Heterogeneous beliefs and routes to chaos in a simple asset pricing model. Journal of Economic Dynamics and Control, 22, 1235-1274.

Casellina, S. and Landini, S. and Uberti, M. (2011), Credit market dynamics: a cobweb model, Computational Economics, 38, 221-239.

Calza, A. and Monacelli, T. and Stracca, L. (2009). Housing finance and monetary policy, European Central Bank, Eurosystem, Frankfurt, Working Paper Series, 1069, 1-49.

Coles, A. and Hardt, J. (2000). Mortgage Markets: Why US and EU Markets are so different, Housing Studies, 15(5), 775-783.

Coulibaly, B. and Li, G. (2009). Choice of Mortgage Contracts: Evidence from the Survey of Consumer Finances, Real Estate Economics, 37(4), 659-673.

Dieci, R. and Westerhoff, F. (2009). Stability analysis of a cobweb model with market interactions, Applied Mathematics and Computation, 215, 2011-2023.

Dieci, R. and Westerhoff, F. (2010). Interacting cobweb markets, Journal of Economic Behavior 83 Organization, $75(3), 461-481$.

Felici, R. and Manzoli, E. and Pico, R. (2012). La crisi e le famglie italiane: un'analisi microeconomica dei contratti di mutuo, Questioni di Economia e Finanza (Occasional Paper), 125, Banca d'Italia, Eurosistema; www.bancaditalia.it.

European Mortgage Federation (2012), Review of Europe's mortgage and housing markets, European Mortgage Federation, Brussels, November.

Koijen, R.S.J. and Van Hemert, O. and Van Nieuwerburgh, S. (2009). Mortgage Timing, Journal of Financial Economics, 93, 292-324.

Leece, D. (2004). Economics of the mortgage market: perspectives on household decision making, Wiley-Blackwell, Oxford, pp. 272.

Mori, M. and Diaz, J. and Ziobrowski, A.J. and Rottke, N.B. (2010). Psychological and Cultural Factors in the Choice of Mortgage Products: A Behavioral Investigation, The Journal of Behavioral Finance, 11, 82-91. 